\title{
A STUDY ON CRITICAL STRENGTH OF THIN-WALLED STEEL FRAMES SUBJECTED TO COMBINATIONS OF VERTICAL AND HORIZONTAL LOADS
}

\author{
By Hiroshi NAKAI*, Masahiko KITAZAWA** and Toshihiro MIKI***
}

\begin{abstract}
This paper reports the in-plane "critical strength" representing the buckling or ultimate strength of thin-walled steel frames subjected to the combined actions of vertical and horizontal loads. To investigate the critical strength of steel frames, an experimental study is performed by using seven portal frame models with thin-walled box cross-section. The critical strengths of portal frames are also inquired on the basis of elasto-plastic and second order analysis including the approximate method for evaluating the local buckling of thin-walled column sections. Through these results, the lower bound of critical strength of frames is clarified in detail. Finally, two approximate methods for estimating critical strength of thin-walled steel frames are proposed herein.
\end{abstract}

\section{INTRODUCTION}

In designing the steel frame structures composed of thin-walled box members, the formula for estimating the ultimate strength of beam-column by using the effective buckling length of column has been presented in not only the Japanese Specification for Highway Bridges ${ }^{1)}$ (thereafter referred to as JSHB) but also almost all other foreign specifications. Particularly, the plastic analysis considering the effects of $P-\Delta$ due to vertical loads, $P$, and buckling displacements, $\Delta$, is recently codified as a design reccomendation of ultimate strength of frames in DIN 18800, Teil II ${ }^{2)}$ and ECCS $^{3) .4)}$.

However, if the plastic analysis ${ }^{6,7)}$ is applied to the steel frames with non-compact and thin-walled cross-section $^{5)}$, it may overestimate the ultimate strength of frames, because the decrease of rigidities of thin-walled cross-section due to the local buckling can not be taken into accounts in such analytical method. Especially, there are many unclarified problems how to estimate the influences of local buckling upon the ultimate strength of thin-walled frames for a case where the bending moment in members is predominant in comparison with the axial force and the difference of load capacities between the initial plastic hinge and plastic mechanism is large.

Inoue, Takenaka, Hasegawa and Nishino ${ }^{8)}$ has dealt with the ultimate strength of steel frames on the basis of the elasto-plastic finite displacement theory and they sustain the validities of design method of frames by using the effective buckling length of column. However, the same kind of problems mentioned in

* Member of JSCE, Dr. Eng., Professor, Dept. of Civil Eng., Osaka City University (Sugimoto 3-3-138, Sumiyoshi-ku, Osaka 558)

** Member of JSCE, Engineer, Design Division, Central Office of Hanshin Expressway Public Corporation (Kitakyutaro-chou 4, Higashi-ku, Osaka 541)

*** Member of JSCE, M. Eng., Research Associate, Dept. of Civil Eng., Osaka City University (Sugimoto 3-3-138, Sumiyoshi-ku, Osaka 558) 
the above can not be avoidable even in the analytical methods ${ }^{9)}{ }^{10)}$ where the propagations of plastic zone in members are taken into considerations.

Therefore, it is necessary to make clear of the critical state for the frames containing the local buckling of columns with thin-walled cross-section as well as the overall buckling of frames.

In this paper, an experimental study is performed by using seven thin-walled frames subjected to the combined vertical and horizontal loads. The critical strength of portal frames are also inquired on the basis of elasto-plastic and second order analysis ${ }^{11)}$.12). Through the examinations of these results, the critical states and corresponding strengths of frames are inquired in detail.

Finally, two alternative design methods for predicting the critical strength of frames are proposed and their validities are checked in comparison with the test results.

\section{EXPERIMENTAL STUDY}

\section{(1) Test specimen}

Seven portal frames, F $1 \sim \mathrm{F} 7$, with the thin-walled box cross-section indicated in Fig. 1 were fabricated as shown in Fig. 2. Every test frames, F $1 \sim$ F 4 and F $5 \sim$ F 7 , have the same dimensions and their plate slenderness, $R_{f}$, i. e.

$$
R_{f}=\left(B / t_{f}\right) \cdot \sqrt{12\left(1-\mu^{2}\right) /\left(k \pi^{2}\right)} \cdot \sqrt{\sigma_{y} / E}
$$

are set as 0.5 and 0.7 , respectively, where $B$ and $t_{f}:$ width and thickness of flange plate (common to beam and column), respectively, $k$ : buckling coefficient of plate elements $(=4.0), E:$ Young's modulus $\left(=2.06 \times 10^{5} \mathrm{MPa}\right)$ and $\mu$ : Poisson's ratio $(=0.3)$.

The relative stiffness, $K$, of column to beam of frame,

$$
K=\left(I_{c y} / h\right) \cdot\left(l / I_{b y}\right)
$$

and the slenderness of column, $\bar{\lambda}_{y}$, i. e.

$$
\bar{\lambda}_{y}=\sqrt{P_{e} / P_{y}}=\left(h_{e} / r_{c y}\right) \cdot(1 / \pi) \sqrt{\sigma_{y} / E} \text {. }
$$

are set as 1.0 and 0.5 , respectively, in order to involve the overall buckling tests of frames reported in Ref.12), where $I_{c y}, I_{b y}$ : geometrical moment of inertia of column and beam, respectively, $l, h:$ span and height of frame, respectively, $P_{y}$ : squash force of column (=cross-sectional area $A_{c} \times$ yield stress $\left.\sigma_{y}\right), P_{e}$ : elastic buckling load of frame, $h_{e}$ : effective buckling

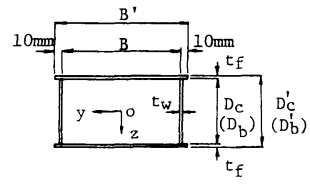

Fig. 1 Cross-section of column (beam) in test frame.

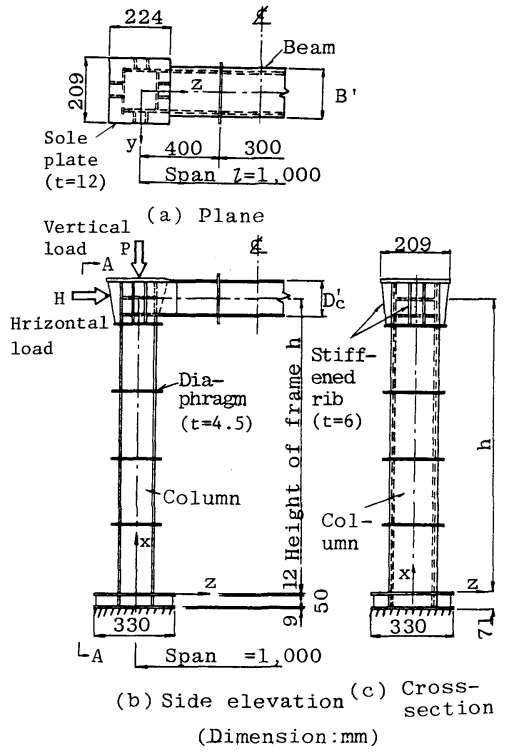

Fig. 2 Details of test frames.

Table 1 Dimensions, cross-sectional properties and parameters of test frames (SS 41).

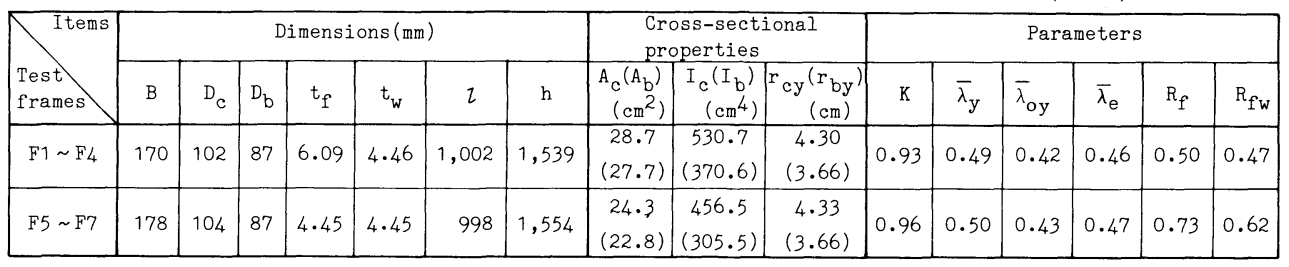

Notes; $B^{\prime}, D_{c}^{\prime}, D_{b}^{\prime}, t_{f}, t_{w}, l, h$ : see Fig.1 2., $A_{c}, A_{b}$ : cross-sectional area of column and beam, respectivey., $I_{c y}, I_{b y}$ : geometrical moment of inertia of column and beam, respectively., $r_{c y}, r_{b y}:$ radius

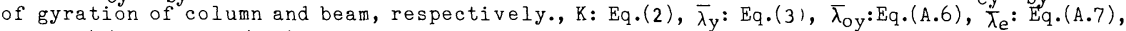
$R_{f}: E q \cdot(1), R_{f w}:$ Eq.(A.4). 
length of column by elastic theory and $r_{c y}$ : radius of gyration of column.

The dimensions, cross-sectional properties and various buckling parameters of test frames are listed in Table 1.

(2) Loading condition

The vertical load, $P$, and horizontal load, $H$, are applied to the test frames in proportional to their intensities as shown in Fig. 2. In order to know the variations of critical strength of frames due to the load ratio, $P / H$, the following relative load ratio

$$
\alpha=\left(P / P_{y}\right) /\left(H / H_{p}\right)
$$

are set within the ranges $\alpha=0 \sim 3.6$, in which $H_{p}$ means the load corresponding to the initial plastic hinge, where a column section of the frame subjected to the horizontal load alone results in the fully plastic state.

These loads, $P_{y}$ and $H_{p}$, of test frames as well as relative load ratio, $\alpha$, are shown in Table 2. The additional figures indicated in the test frames of this table are categorized as follows;

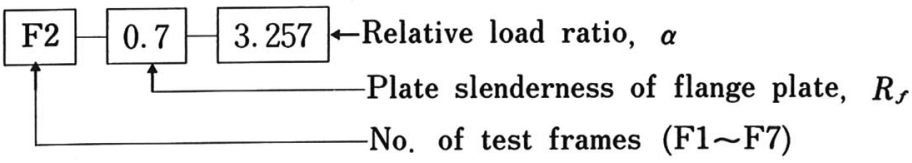

\section{( 3 ) Loading device}

The same loading device (seePhoto 1) as detailed in Ref. 12) was utilized for the tests. Firstly, through the experiments in the elastic region, load ratio, stress distribution and difference between axial forces in both the columns were checked in comparison with those of the elastic linear theory. Thereafter, the vertical and horizontal loads were gradually increased up to the failure of test frames.

(4) Mechanical property and initial imperfection of test frames

a) Mechanical property

The test frames were assembled by eight different steel plates with steel grade SS 41, so that the tensile tests of these plates were carried out by 44 coupon specimens, JIS No. 5 . The averages of mechanical properties such as Young's modulus $E$, Poisson's ratio $\mu$ and yield stress $\sigma_{y}$, are summarized in Table 3 .

b) Initial imperfection

The initial deflections at the central line of columns and the top and bottom flange plates of columns of test frames were measured prior to the failure tests.

All the specimens have the initial deflection of which modes are sway ones having the horizontal deflection at the top. The magnitude of initial deflection, $\delta_{0} / h$, at their tops are within the ranges from

Table 2 Loading condition of test frames.

\begin{tabular}{|c|c|c|}
\hline Items & $\begin{array}{l}\text { Relative } \\
\text { load ratio } \\
\alpha\end{array}$ & $\begin{array}{l}\text { Critical } \\
\text { loads } \\
(\mathrm{KN})\end{array}$ \\
\hline F1-0.5-3.57 & 3.565 & \multirow{3}{*}{$\begin{array}{l}P_{y}=819 \\
H_{p}=76\end{array}$} \\
\hline F2-0.5-1.22 & 1.222 & \\
\hline F3-0.5-0.40 & 0.396 & \\
\hline$F_{4}-0.5-0$ & 0 & \multirow{4}{*}{$\begin{array}{l}P_{y}=715 \\
H_{p}=65\end{array}$} \\
\hline F5-0.7-3.26 & 3.257 & \\
\hline F6-0.7-1.16 & 1.156 & \\
\hline F7 $-0.7-0.35$ & 0.347 & \\
\hline
\end{tabular}

Notes; $\alpha: \mathrm{Eq} .(4)$

$P_{y}:$ Squash force of column

$\mathrm{H}_{\mathrm{p}}$ :First hinge load of frames

subjected to horizontal load.

Table 3 Elastic modulus and yield point of test frames (SS41).

\begin{tabular}{|c|c|c|c|}
\hline \multicolumn{2}{|c|}{ Elastic modulus } & \multicolumn{2}{|c|}{ Yield point $(\mathrm{MPa})$} \\
\hline $\mathrm{E}(\mathrm{MPa})$ & $\mu$ & $\mathrm{F} 1 \sim \mathrm{F} 4$ & F5 F7 \\
\hline $2.1 \times 10^{5}$ & 0.27 & 285 & 294 \\
\hline
\end{tabular}

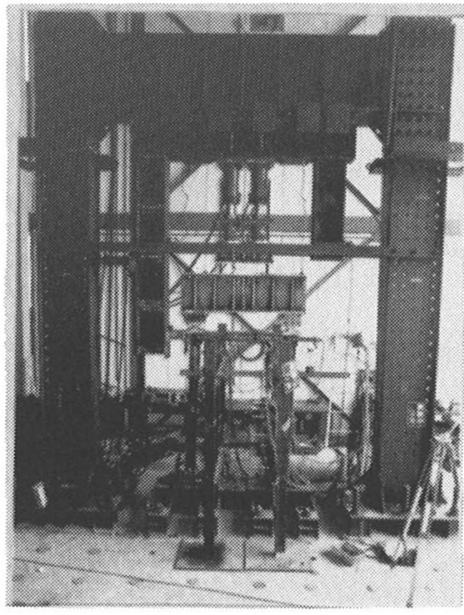

Photo 1 Experimental apparatus. 
$1 / 5,130$ to $1 / 187$ and their average is reduced to $1 / 698$. The average of the maximum initial deflections in the flange plates is also less than that of the fabrication tolerance, B/150, of JSHB and their average is $0.752 \cdot \mathrm{B} / 150$.

While, the maximum values of compressive residual stresses, $\sigma_{r c}$, is thought to be $0.35 \cdot \sigma_{y}$, because the cross-sections of columns of test frames used in this experimental study have almost the same dimensions as the stub-column specimens as detailed in Ref.13).

\section{TEST RESULT}

\section{(1) Test frames after collapse}

The collapse patterns of test frames, $\mathrm{F}_{1} \sim \mathrm{F} 4$, after failure tests are shown in Fig. 3. The local bucklings are observed in the top and bottom flange plates of columns in the test frames, F 1 and F 2, having the large load ratio, $\alpha$. This means that the local buckling at the top and bottom flange plates is taken place simultaneously at the ultimate state of test frames, because the columns are in the situation of almost uniaxially compression caused by the significant vertical loads.

On the other hand, the local buckling of test frames, F 3 and F 4, having the smaller load ratio, $\alpha$, are only appeared at the bottom plate of columns. In this case, it is considered that the frames collapse due to the local buckling at bottom plate in which the remarkable bending moment occurs.

\section{( 2 ) Load-displacement curves}

The relationships between the horizontal load, $H$, and sway displacement, $\delta$, of test frames are shown in Figs. 4 5, where $P$ and $\delta$ are non-dimensionalized by the load corresponding to the initial plastic hinge, $H_{\rho}$, and height of frames, $h$, respectively. $H-\delta$ curves according to the elasto-plastic finite displacement analysis ${ }^{14)}$ are also plotted by the solid lines in these figures.

These figures show that the influences of local buckling are not observed in the test frames, $\mathrm{F} 1$ and $\mathrm{F} 5$, having the large load ratio, $\alpha$, and these experimental $H-\delta$ curves well coincide with the analytical ones. Besides, the experimental curves of test frames, F 3, F 4 and F 7 , having the smaller load ratio, $\alpha$, begin to deviate from the analytical curves near $80 \%$ of the ultimate loads due to the local buckling. The

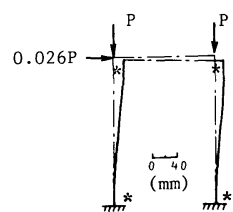

(a) F1-0.5-3.57

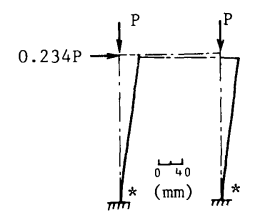

(c) $F 3-0.5-0.40$

*: Positions of local buckling

Fig. 3 Collapse modes of test frames $\mathrm{F}_{1} \sim \mathrm{F}_{4}$.

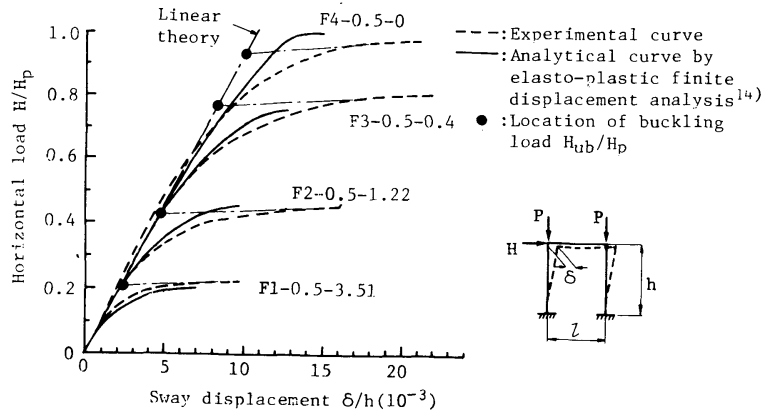

Fig. $4 H-\delta$ curves of test frames $\mathrm{F}_{1} \sim \mathrm{F} 4$

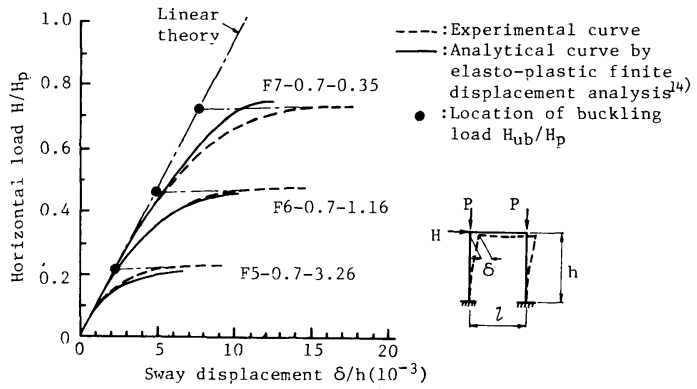

Fig. $5 H-\delta$ curves of test frames $\mathrm{F} 5 \sim \mathrm{F} 7$. 
difference between both the curves has a tendency to increase in accordance with the decrease of load ratio, $\alpha$.

Therefore, it should be noted that the critical state is greatly affected by the decrease of rigidities of frame due to the local buckling, which will not be disregarded and is an important phenomenon for developing the design method of thin-walled frames.

\section{(3) Critical strength}

Two typical strengths can be obtained on the basis of the critical states of test frames. One is the buckling strength, $\left(P_{u b}, H_{u b}\right)$, where the sway displacement of frame begins to increase rapidly. Then, it can be taken as the load corresponding to the intersection of linear $H-\delta$ curve and a tangent line of experimental $H-\delta$ curve near the ultimate state as illustrated in Figs. 4 5. The other is the ultimate strength, $\left(P_{u}, H_{u}\right)$, which can be obtained as the maximum loads by the experimental studies. The representative of these critical strengths, $\left(P_{u b}, H_{u b}\right)$ and $\left(P_{u}, H_{u}\right)$, are referred to as $\left(P_{c r}, H_{c r}\right)$ in foregoing discussions.

The relationships between horizontal critical strength $\left(H_{u b}, H_{u}\right)$ and vertical ones $\left(P_{u b}, P_{u}\right)$ can be written by using the relative load ratio, $\alpha$, as follows;

$P_{u b} / P_{y}=\alpha\left(H_{u b} / H_{p}\right), P_{u} / P_{y}=\alpha\left(H_{u} / H_{p}\right)$

The test results of these critical strengths are listed in Table 4. The critical strengths of test frames,

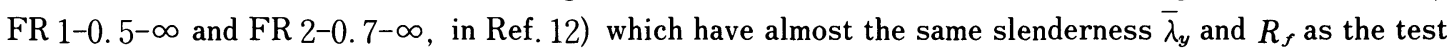
frames, $\mathrm{F} 1 \sim \mathrm{F} 4$ and $\mathrm{F} 5 \sim \mathrm{F} 7$, are also shown in this table.

Fig. 6 shows the interaction curve, $P_{c r} / P_{y}-H_{c r} / H_{\rho}$, between horizontal and vertical strengths. The initial yield line and the curve corresponding to the initial plastic hinge according to the elastic linear theory are also plotted in this figure.

It can be seen from this figure that the critical strengths of test frames, F $5 \sim \mathrm{F} 7\left(R_{f}=0.7\right)$, are smaller than those of test frames, F $1 \sim \mathrm{F} 3 \quad\left(R_{f}=0.5\right)$, by $5 \sim 8 \%$ for the difference of plate slendernesses, $R_{f}$, and the difference becomes larger in accordance with the decrease of load ratio, $\alpha$.

In all the test frames, the ultimate strength is larger than the buckling strength by $2 \sim 8 \%$ and the test frames have the redundant strength up to the ultimate state from critical state in which the sway displacements begin to increase rapidly.

Both the critical strengths lay on the outside of initial yield line in the range where $\alpha<5 / 4$ and the redundant strengths after the initial yield load tend to become larger in accordance with the decrease of load ratio, $\alpha$. This redundancy may correspond to the shape-factor from initial yield state to fully plastic state at the fixed end of columns with remarkable bending moment. While, the critical strength is smaller than the initial yeild load by $5 \sim 15 \%$ due to the influence of $P-\Delta$ effect initiated by the vertical loads in the ranges where $\alpha>4$.

The curve for the initial plastic hinge gives the upper bounds of buckling strength. This indicates that the thin-walled frames will reduce to the critical state in which the sway displacements increase rapidly by

Table 4 Test results of critical strength.

\begin{tabular}{|c|c|c|c|c|c|}
\hline Items & Buckling & strength & Ultimate & strength & Difer- \\
\hline & (1) $: \frac{\mathrm{H}_{\mathrm{ub}}}{\mathrm{H}_{\mathrm{p}}}$ & (2) $: \frac{\mathrm{P}_{\mathrm{ub}}}{\mathrm{P}_{\mathrm{y}}}$ & (3) $: \frac{\mathrm{H}_{u}}{\mathrm{H}_{\mathrm{p}}}$ & (4) $: \frac{\mathrm{P}_{u}}{\mathrm{P}_{\mathrm{y}}}$ & $\begin{array}{l}\text { ence } \\
E_{\mathrm{r}}(\%)\end{array}$ \\
\hline FR1-0.5- $\infty$ & 0 & 0.900 & 0 & 0.940 & 4.3 \\
\hline F1 $-0.5-3.57$ & 0.210 & 0.749 & 0.222 & 0.791 & 5.3 \\
\hline F2 $-0.5-1.22$ & 0.430 & 0.525 & 0.465 & 0.568 & 7.6 \\
\hline F3 $-0.5-0.40$ & 0.780 & 0.309 & 0.805 & 0.319 & 3.1 \\
\hline F4 - $-0.5-0$ & 0.910 & 0 & 0.974 & 0 & 6.6 \\
\hline FR2 $-0.7-\infty$ & 0 & 0.850 & 0 & 0.887 & 4.2 \\
\hline F5 $-0.7-3.26$ & 0.210 & 0.684 & 0.225 & 0.733 & 6.7 \\
\hline F6 $-0.7-1.16$ & 0.455 & 0.526 & 0.469 & 0.542 & 3.0 \\
\hline F7 $-0.7-0.35$ & 0.710 & 0.246 & 0.726 & 0.252 & 2.2 \\
\hline
\end{tabular}

Notes; $E_{\mathbf{r}}=\left\{\sqrt{(3)^{2}+(4)^{2}}-\sqrt{(1)^{2}+(2)^{2}}\right\} / \sqrt{(3)^{2}+(4)^{2}}$, ,

FR1 and FR2 show the test results obtained from Ref.12).

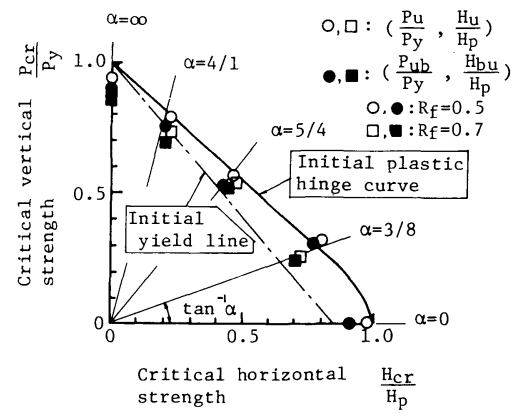

Fig. 6 Test results of critical strength. 
the reduction of rigidity of frame as soon as a column section reachs the fully plastic or local buckling states.

\section{CRITICAL STRENGTH ANALYSIS OF THIN-WALLED PORTAL FRAMES}

\section{(1) Analytical method}

a) Analytical method

The analysis for the critical strength of frames is based on the transfer matrix method ${ }^{12)}$ formulated by the elasto-plastic and second order analytical theory. Then, the following three assumptions are added in this paper;

(i) The upper bound of critical load of frames can be approximated by the load corresponding to the initial plastic hinge load.

(ii) The initial plastic hinge always initiates in the column members prior to the beam members of frame.

(iii) The reduction of rigidity of beam member due to the propagation of plastic zone is so small that the beam member always remains within the elastic ranges.

Then, referring to Ref. 12), the analytical model of portal frames subjected to both the vertical and horizontal loads can be idealized into a cantilever beam-column with rotational restraint, $K_{\varphi}\left(=6 \mathrm{E} I_{b y} / l\right)$, compressive load $P^{\prime}$ and horizontal load $H^{\prime}$ at the top as illustrated in Fig. 7(b), where the rotational restraint, $K_{\varphi}$, is defined as the bending moment which gives the unit rotational angle at both the ends of beam. The induced loads, $P^{\prime}$ and $H^{\prime}$, can be calculated by using the applied loads $P$ and $H$ on the basis of elastic linear theory as follows;

$P^{\prime}=P+3 H \cdot(h / l) /(6+K), H^{\prime}=H / 2$

The boundary conditions at the top and fixed ends of this analytical model can be represented as follows ; At fixed end of column $(x=0): u=0, w=0, \varphi=0$

At top of column $(x=h): N-P^{\prime}=0, Q-H^{\prime}=0, M-K_{\varphi} \varphi=0$

where $u$ : axial displacement, $w:$ deflection, $\varphi:$ deflection angle, $N:$ axial compressive force and $M$ : bending moment.

b) Method of evaluating critical strength

In addition to the above, the following two types of critical strengths are evaluated in this analysis;

(i) $\left(P_{u 1} / P_{y}, H_{u_{1}} / H_{p}\right)$ : This pair of critical strength respectively represents the vertical and horizontal critical loads corresponding to the ultimate states (hereafter referred to as the critical stateI) in which a cross-section of column reduces to the fully plastic or local buckling states. By reffering to Ref. 12), this critical strength can be approximated by the ultimate interaction curve ${ }^{11)}$ of box stub-columns subjected to compression and bending.

(ii) $\left(P_{u 2} / P_{y}, H_{u 2} / H_{\rho}\right)$ : This pair of critical strength means the vertical and horizontal critical strength representing the instability state of frame (hereafter referred to as the critical state- II), which

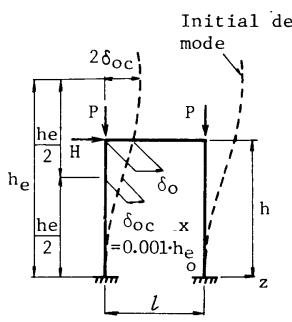

(a) Portal frame with initial imperfection

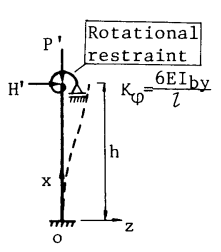

(b) Analytical model

Fig. 7 Analytical model of portal frame subjected to combined loads.

Table 5 Critical strength of test frames by elastoplastic second order analysis.

\begin{tabular}{|c|c|c|c|}
\hline \multirow{2}{*}{$\begin{array}{l}\text { Items } \\
\text { Test } \\
\text { frames }\end{array}$} & \multicolumn{2}{|c|}{$\begin{array}{l}\text { Critical strength } \\
\text { by analysis }\end{array}$} & \multirow{2}{*}{$\begin{array}{l}\text { Errors } \\
\text { for test } \\
\text { results }\end{array}$} \\
\hline & $\mathrm{H}_{\mathrm{cr}} / \mathrm{H}_{\mathrm{p}}$ & $\mathrm{P}_{\mathrm{cr}} / \mathrm{P}_{\mathrm{y}}$ & \\
\hline FR1 $-0.5-\infty$ & 0 & 0.878 & 2.6 \\
\hline F1 $-0.5-3.57$ & 0.195 & .696 & 7 \\
\hline F2 $-0.5-1.22$ & 0.419 & 0.512 & 2. \\
\hline F3 $-0.5-0.40$ & 0.711 & 0.282 & 8.8 \\
\hline $\mathrm{F} 4-0.5-0$ & 0.940 & 0 & -3.3 \\
\hline FR2-0.7- $\infty$ & 0 & 0.827 & 2.8 \\
\hline F5 $-0.7-3.26$ & 0.198 & 0.646 & 5.6 \\
\hline F6 $-0.7-1.16$ & 0.410 & 0.474 & 9.9 \\
\hline F7 - $-0.7-0.35$ & 0.705 & 0.245 & 0.7 \\
\hline
\end{tabular}


can be obtained by the divergence condition of sway displacement of frames.

Hereafter, the smaller value of either $\left(P_{u 1} / P_{y}, H_{u 1} / H_{p}\right)$ or $\left(P_{u 2} / P_{y}, H_{u 2} / H_{p}\right)$ is referred to as the critical strength and is expressed by the representative symbol $\left(P_{c r} / P_{y}, H_{c r} / H_{p}\right)$.

(2) Parametric study on critical strength

a) Critical strength of test frames

The test frames, F $1 \sim \mathrm{F} 7$, as detailed in Tables 1 and 3 were analyzed by altering the relative load ratio, $\alpha$. From these parametric analyses, the critical strength $\left(P_{c r} / P_{y}, H_{c r} / H_{p}\right)$ corresponds to $\left(P_{u 1} / P_{y}, H_{u 1} / H_{p}\right)$ for all the test frames, because the column slendernesses, $\bar{\lambda}_{y}$, have the relatively small values. These analytical results, $\left(P_{c r} / P_{y}, H_{c r} / H_{p}\right)$, are listed in Table 5 and are plotted in Fig. 8 together with the experimental results of buckling strength.

It can be seen from this figure that the critical strength by this analysis well coincides with the experimental results within the errors $-3 \sim 10 \%$. Therefore, the critical strength, which is governed by the rapid reduction of rigidity of frames due to the local buckling, can be predicted by this analytical method with high accuracy.

b) Critical Strength of frames with large column slenderness

The critical strength of frames with large column slenderness, $\bar{\lambda}_{y}$, were investigated under the conditions of various load ratio, $\alpha$. These frames under analysis have the same cross-sectional dimensions as the test frames, $\mathrm{F} 5 \sim \mathrm{F} 7$, and the column slenderness $\bar{\lambda}_{y}=1.0$.

Table 6 shows the variations of two critical strengths, $\left(P_{u 1} / P_{y}, H_{u 1} / H_{p}\right)$ and $\left(P_{u 2} / P_{y}, H_{u 2} / H_{p}\right)$, of slender frames due to load ratio, $\alpha$. Fig. 9 also shows the relationship between the horizontal and vertical critical strengths, $P_{u 1}-H_{u 1}$ and $P_{u 2}-H_{u 2}$.

In the ranges where $\alpha=5 \sim \infty,\left(P_{u 2} / P_{y}, H_{u 2} / H_{p}\right)$ gives the lower bound of critical strength, and then the frames reach the critical state- II prior to the state- I because of the effects of $P-\Delta$ by vertical loads. Whereas, $\left(P_{u 1} / P_{y}, H_{u 1} / H_{p}\right)$ gives the minimum critical strength and a cross-section of column becomes the ultimate state before the critical state- II of frames in the range where $\alpha<5$. It is worth to note that the interaction curve $P_{c r} / P_{y}-H_{c r} / H_{p}$ has the almost linear relationship.

\section{PROPOSITION FOR CRITICAL STRENGTH OF THIN-WALLED STEEL FRAMES}

\section{(1) Approximation of interaction curve for critical strength of frame}

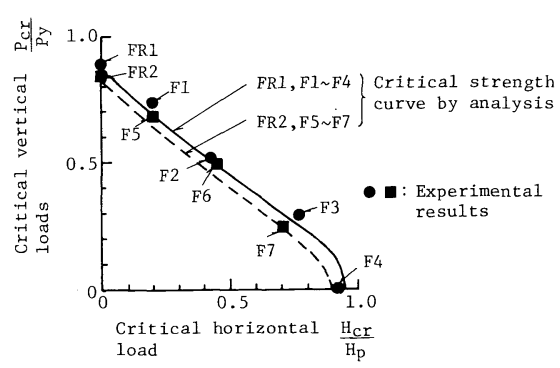

Fig. 8 Comparison of critical strength of frames by experiment with by elasto-plastic second order analysis.

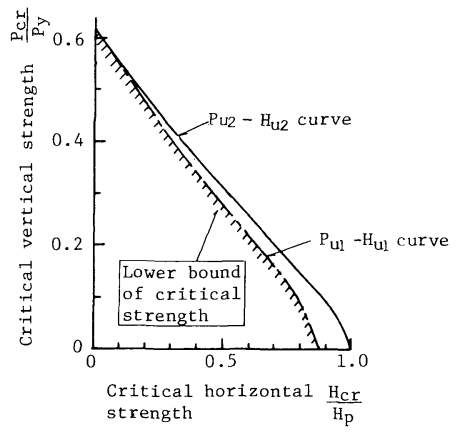

Fig. 9 Critical strength curves of slender frame $\left(\bar{\lambda}_{y}=1.0\right)$.

Table 6 Variation of critical strength of slender frames due to load ratio $\alpha$.

\begin{tabular}{|c|c|c|c|c|c|}
\hline Strength $a$ & $\infty$ & 3 & 1 & $1 / 3$ & 0 \\
\hline$\left(\mathrm{p}_{\mathrm{u} 1} / \mathrm{P}_{\mathrm{y}}, \mathrm{H}_{\mathrm{u} 1} / \mathrm{H}_{\mathrm{p}}\right)$ & - & $(0.493,0.164)$ & $(0.363,0.363)$ & $(0.208,0.624)$ & $(0,0.874)$ \\
\hline$\left(\mathrm{P}_{\mathrm{u} 2} / \mathrm{P}_{\mathrm{y}}, \mathrm{H}_{\mathrm{u} 2} / \mathrm{H}_{\mathrm{p}}\right)$ & $(0.614,0)$ & $(0.505,0.168)$ & $(0.381,0.381)$ & $(0.223,0.669)$ & $(0,1.0)$ \\
\hline
\end{tabular}


a) Approximation of interaction curve

Based upon the above discussion, the relationship between critical load and initial plastic hinge load of frames can generally be plotted as shown in Fig. 10. Then, the following approximate method for estimating the critical strength of thin-walled frames can be proposed.

At first, the vertical critical load, $P_{u}$, can be calculated from Eq. $(\mathrm{A} \cdot 1)^{12)}$ in Appendix. The critical load, $H_{u}$, can be given as follows, since the critical state of frames subjected to the horizontal load alone corresponds to the critical state- I ;

$H_{u}=k_{\rho l} \cdot H_{p}$

in which $k_{p l}$ is the reduction factor for taking into accounts of the local buckling as detailed by Eq. (A.5) in Appendix.

If the interaction curve, $P_{c r} / P_{u}-H_{c r} / H_{u}$, which modifying the interaction curve, $P_{c r} / P_{y}-H_{c r} / H_{y}$, is assumed to coincide with the initial plastic hinge curve, the critical loads of frames can be deduced by the following equation ;

$$
H_{c r} / H_{u}=H_{0} / H_{p}, P_{c r} / P_{u}=P_{0} / P_{y}
$$

where $P_{0} / P_{y}$ and $H_{0} / H_{p}$ respectively correspond to the vertical and horizontal loads as a point, $Q$, on the initial plastic hinge curve through the change of relative load ratio into $\alpha^{\prime}$ as shown in Fig. 10, which gives;

$$
\alpha^{\prime}=\alpha \cdot\left(H_{u} / H_{p}\right) /\left(P_{u} / P_{y}\right)
$$

b) Comparison of approximate method with test results

The approximate interaction curve is plotted by using Eq. (9). Fig. 11 shows the comparisons of this approximate interaction curve with test results listed in Table 4. This figure shows that the approximate interaction curve well coincides with the test results.

Since the initial plastic hinge curve and the critical strength, $H_{u}$, can easily be obtained, it is the important problems how to estimate the critical vertical strength, $P_{u}$, in applying this method to the design of various types of frames.

\section{(2) Method for evaluating critical strength by beam-column formula}

a) Beam-column formula

The ultimate strength of beam-column in the frames subjected to combined loads is generally given by the design formula in JSHB and other foreign specifications as follows;

$\left(N / P_{u}\right)+\left(M / M_{u}\right) /\left(1-N / P_{e}\right)=1$

where $N, M$ : compressive force and bending moment applied to beam-columns, respectively, $P_{u}$ : ultimate strength of column and $M_{u}$ : ultimate bending moment of beam-column.

In the test frames, the applied stress-resultants, $N$ and $M$, have the maximum values at the fixed end of right hand side of column in Fig. $7(\mathrm{a})$, which lead to;

$$
N=P+3 H \cdot(h / l) /(6+K), \quad M=H h \cdot(3+K) /\{2(6+K)\} \cdots \cdots
$$

Although the bending moment, $M$, in Eq. (11) should be taken as the equivalent moment by modifying the bending moment with triangle distribution into the uniform distribution, the maximum bending moment in

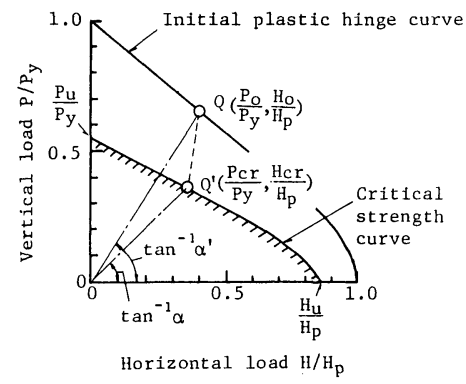

Fig. 10 Approximate method for evaluating critical strength of frames.

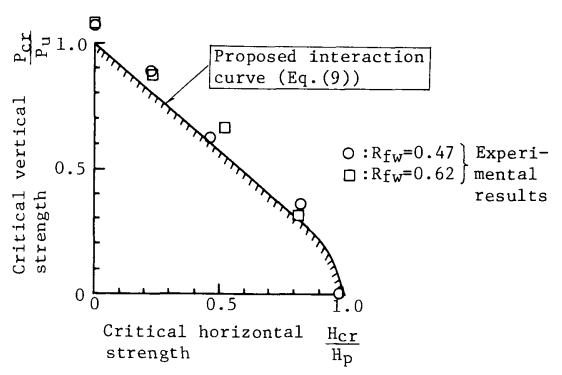

Fig. 11 Comparison of approximate interaction curve of critical strength of frame with test results. 
Eq. $(12 \cdot b)$ at the fixed end of column is used in this paper for the sake of simplicity.

According to Ref. 12), the ultimate strength of column, $P_{u}$, by JSHB may underestimate its strength, because the effective buckling length of column, $h_{e}$, is determined much more conservatively. Then, the rational ultimate strength, $P_{u}$, can be calculated by Eq. (A-1) in Appendix. While, the ultimate bending moment, $M_{u}$, of columns in Eq. (11) can be decided from the fully plastic moment, $M_{p}$, and the reduction coefficient, $k_{p l}$, by referring Eq. (8) as follows;

$M_{u}=k_{p l} \cdot M_{p}$

b) Comparison of beam-column formula with test results

For the sake of simplicity, the following beam-column formula ignoring a term, $1 /\left(1-P / P_{e}\right)$, in Eq. (11), which corresponds to the nonlinear behavior of beam-column, is compared with the test results listed in Table 4.

$\left(N / P_{u}\right)+\left(M / M_{u}\right)=1$

The comparisons of the above equation with test results and JSHB's curve given by Eq. (11) are shown in Fig. 12. This figure indicates that the approximate method by using Eq. (14) gives the excellent results for the test results. While, the JSHB's curve gives the more conservative strength for the test results, because the ultimate strength of column, $P_{u}$, is more or less underestimated and the ultimate bending moment, $M_{u}$, is taken as the yield moment instead of fully plastic moment.

This approximate method can be utilized as a beamcolumn formula based upon the ultimate strength formula of JSHB without complicated procedures in comparison with

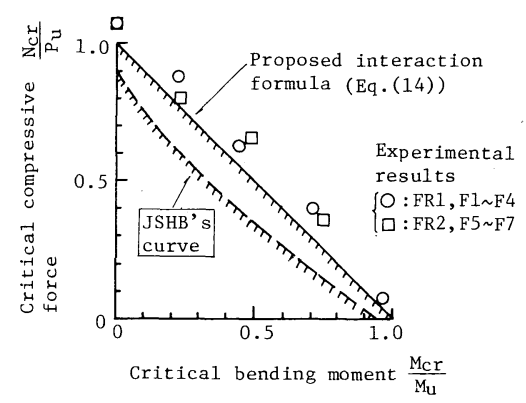

Fig. 12 Comparison of test results with interaction formula of beam-column. the above interaction curve.

Accordingly, this design formula will also be useful for the design method of frames.

\section{CONCLUDING REMARKS}

In this paper, the collapse behaviors and the critical strength of thin-walled steel frames were reported by conducting the experimental and theoretical studies. The main conclusions can be summarized as follows ;

(1) In all the test frames, the load corresponding to the initial plastic hinge gives the upper bound of the critical load, which is governed by the decrease of rigidity of frame due to the local buckling.

(2) An approximate interaction curve between vertical and horizontal loads applied to frame is proposed for estimating the critical strength of thin-walled frames.

( 3 ) The beam-column formula for the critical strength of frames according to JSHB is conservative against the test results.

( 4 ) By modifying the beam-column formula given by JSHB, an alternative approximate method is also proposed for estimating the critical strength of frames.

(5) The validities of two approximate methods in (2) and (4) are checked by the comparison with the test results.

\section{ACKNOWLEDGMENTS}

In conducting the experimental study, the authors would like to appreciate the energetic cooperations by Mr. Y. Kanazawa, Kawada Industry Corporation, a formerly student of Osaka City University. 


\section{APPENDIX-CALCULATION METHOD OF CRITICAL STRENGTH OF STEEL FRAMES SUBJECTED TO VERTICAL LOAD}

The critical strength of steel frames under the vertical loads, $P$, can be obtained from Ref. 12) as follows;

$$
P_{u} / P_{y}=\min \left\{P_{c 0} / P_{y} ; P_{c 1} / P_{y}\right\}
$$

where $P_{c 0} / P_{y}$ and $P_{c 1} / P_{y}$ are the ultimate and buckling strengths of frames, respectively, which gives;

$$
\left.\begin{array}{rl}
P_{c 0} / P_{y} & =1.0 \quad, \quad \bar{\lambda}_{e}<0.2 \\
& =1.0-0.545\left(\bar{\lambda}_{e}-0.2\right), \quad 0.2<\bar{\lambda}_{e} \leq 1.0 \\
& =1 /\left(0.773+\bar{\lambda}_{e}^{2}\right) \quad, \quad \bar{\lambda}_{e}>1.0 \\
P_{c 1} / P_{y} & =P_{c 0} / P_{y} \quad, \quad k_{p 1} \geq 1-\left(0.48 \bar{\lambda}_{e}\right)^{2} \\
& =P_{c 0} / P_{y}\left\{k_{p 1}+\left(0.48 \bar{\lambda}_{e}\right)^{2}\right\}, \quad k_{p 1}<1-\left(0.48 \bar{\lambda}_{e}\right)^{2}
\end{array}\right\}
$$

and $k_{p 1}$ is the non-dimensionalized ultimate strength of box stub-column under the axial compression.

If the plate slenderness, $R_{f w}$, of box cross-section is defined as

$$
R_{f w}=\left(B / t_{f}\right) \cdot \sqrt{12\left(1-\mu^{2}\right) /\left(k_{f w} \pi^{2}\right)} \cdot \sqrt{\sigma_{y} / E}
$$

then $k_{\rho 1}$ can be given as follows ${ }^{13)}$;

$$
\left.\begin{array}{rl}
k_{\rho 1} & =1.0 \\
& =0.542 R_{f w}^{3}-1.248 R_{f w}^{2}+0.412 R_{f w}+0.968,
\end{array} \quad \begin{array}{l}
R_{f w} \leq 0.3 \\
0.3<R_{f w} \leq 1.3
\end{array}\right\}
$$

where $k_{f w}$ is the elastic buckling coefficient of box stub-column ${ }^{13)}$.

Furthermore, if the column slenderness $\bar{\lambda}_{0 y}$ is given as the function of height of frames, $h$,

$$
\bar{\lambda}_{0 y}=\left(h / r_{c y}\right)(1 / \pi) \cdot \sqrt{\sigma_{y} / E} \text {. }
$$

then $\bar{\lambda}_{e}$ can be calculated from the following equations;

$$
\left.\begin{array}{rlrl}
\bar{\lambda}_{e} & =\bar{\lambda}_{0 y} & & \bar{\lambda}_{0 y} \leq 0.3 \\
& =\bar{\lambda}_{0 y}(8+K) / 7-(3 / 70)(1+K), & 0.3<\bar{\lambda}_{0 y} \leq 0.9
\end{array}\right\}
$$

where $K$ is the relative stiffness of column to beam of frame in Eq. (2).

\section{REFERENCES}

1) Japanese Road Association: Specifications for Highway Bridges (JSHB), Feb. 1980.

2) Din 18800 Teil II : Stabilitätsfalle, Knicken von Staben und Stabwerken, April 1981.

3) European Convention for Constructional Steelwork: European Recommendations for Steel Construction, March 1979.

4) European Convention for Constructional Steelwork : Eurocode 3, Common Unified Code of Practice for Steel Structures, Draft, July 1983

5) Kato, B., Akiyama, H. and Kitazawa, S. : Deformation Characteristics of Box-Shaped Steel Members Influenced by Local Buckling, Proc. of AIJ, No. 268, pp.71 76, June 1978.

6) Harrison, H. B. : The Elastic-Plastic Analysis of Plane Flexural Frames, Fritz Engineering Laboratory Report No. 297.16, Lehigh University, Institute of Research, July 1965.

7) American Society of Civil Engineers : Plastic Design in Steel, A Guide and Commentary, ASCE-WRC, Manuals and Reports on Engineering Practice No.41, 1971.

8) Inoue, J., Takenaka, H., Hasegawa, A. and Nishino, F. : Accurcay of the Effective Length based Member Design for the Overall Strength of Structures, The 31 st Structural Engineering Symposiumof JSCE, Vol. 31 A, pp. 123 132, March 1985.

9) Komatsu, S. and Sakimoto, T. : Nonlinear Analysis of Spacial Frames Consisting of Members with Closed Cross-Sections, Proc. of JSCE, No.252, pp. 143 157, Aug. 1976.

10) Fujita, Y., Ohtsubo, H. and Yuhara, T. : Plastic Design of Steel Structures (10 th Report)-Finite Element Analysis of Inelastic Large Deflection Behavior of Inplane Frame Structure, Journal of the Society of Naval Architects of Japan, No. 126, pp. 275 283, Nov. 1979 .

11) Nakai, H., Kitada, T. and Miki, T. : Interaction Curve of Thin-Walled Box Stub-Columns subjected to Compression and Bending for Applying to Overall Buckling Analysis of Columns, Proc. of JSCE, Structural Eng./Earthquake Eng., Vol. 2 , No. 2, pp. $311 \mathrm{~s} \sim 319 \mathrm{~s}$, Sept. 1985.

12) Nakai, H., Emi, S. and Miki, T. : In-Plane Critical Strength of Thin-Walled Steel Frames subjected to Vertical Loads, Proc. of JSCE, Structural Eng./Earthquake Eng., Vol.3, No. 1, April 1986.

13) Nakai, H., Kitada, T. and Miki, T. : Ultimate Strength of Thin-Walled Box-Stub Columns, Proc. of JSCE, Structural 
Eng. /Earthquake Eng., Vol.2, No. 1, pp. 1 s 11 s, April 1985.

14) Nakai, H., Miki, T. and Ohgaki, K. : An Analytical Method for Critical Strength of Thin-Walled Steel Frames, Memoirs of the Faculty of Engineering, Osaka City University, Vol.26, pp.233 250, Dec. 1985. 